\title{
Chinese Learners' Pronunciation Problems and Listening Difficulties in English Connected Speech
}

\author{
Danxin Liang ${ }^{1}$ \\ ${ }^{1}$ College of Foreign Studies, Guangzhou University, Guangzhou Higher Education Mega Center, Guangzhou, P. \\ R. China \\ Correspondence: Danxin Liang, College of Foreign Studies, Guangzhou University, 230Waihuanxi Road, \\ Guangzhou Higher Education Mega Center, Guangzhou, P. R. China. Tel: 86-135-2761-3008. E-mail: \\ 13527613008@139.com
}

Received: January 4, 2015 Accepted: May 12, 2015 Online Published: June 13, 2015

doi:10.5539/ass.v11n16p98 URL: http://dx.doi.org/10.5539/ass.v11n16p98

This study belongs to a research subject "Designing a Tool for Diagnosing Weakness in English Listening Comprehension by Chinese Learners". The subject is funded by Guangdong Provincial Social Science Association (GD11XWW07) and Guangzhou Educational Bureau (11A116). 2012-2015. Granted CNY100,000 in total.

\begin{abstract}
The study investigated the impact of mother tongue on Chinese EFL learners' English pronunciation in making connected speech, and the influence of pronunciation on listening comprehension. Fifty university students of English major were assigned to listen to 25 sentences which are spoken in normal speech and include different sound variations. For further analysis, they were required to read the sentences aloud and have their reading recorded in the meantime. The reading results indicated that the subjects' performance of pronunciation in making connected speech was poor, negatively affected by their mother tongue. The equally disappointing results of the listening test denoted that the subjects' performance of listening comprehension was positively correlated to their skills of pronunciation. Correspondingly, it is attested that negative transfer of mother tongue would lead to substandard pronunciation of English connected speech and unsatisfactory accomplishment of listening comprehension.
\end{abstract}

Keywords: Chinese EFL learner, connected speech, pronunciation problems, listening difficulty, sound variations

\section{Introduction}

Listening and speaking are the language skills closely integrated and simultaneously occurring. One's intelligible oral output can lead to others' real-time successful auditory interpretation. Meanwhile, smooth processing of the oral message can in turn foster further communication. So transmission of intelligible verbal message primarily guarantees fluid oral-auditory interaction. Apparently, the crux of interaction is one's speaking proficiency. As the fundamental and indivisible part of speaking, pronunciation must be attached weight to. Though nice or native-like pronunciation is not equated with good speaking ability, it is instrumental to better comprehension of oral communication because listeners do depend on perspicuous sounds to promote input processing.

However, there are some phonetic challenges that Chinese EFL learners are inclined to confront in pronunciation. These challenges are pertinent to 1) certain individual vowels and consonants which do not occur in Chinese or are pronounced differently in Chinese; 2) vowel combinations and consonant clusters which are not allowed by Chinese phonotactic constraints; 3) sound variations in forms of liaison, weak form, elision and assimilation in connected speech. Native Chinese EFL learners who cannot overcome these obstacles find it hard to speak pure, native-like English.

Poor pronunciation in the target language would undoubtedly degrade the effect of relevant oral-auditory interaction. Then, would a person's mediocre pronunciation have bad influence on his/her own listening comprehension, bringing about unsatisfactory listening performance and causing listening difficulty? Would the negative transfer of one's mother tongue not only affect his/her pronunciation but also have bad impact on 
his/her listening potentiality? These are the questions the author attempts to investigate in this research.

What's more, with years' experience of intermediate-advanced English pronunciation teaching, the author has perceived that it's most difficult for Chinese students to imitate the pronunciation occurring in a fast connected speech. So, the present study will give specific attention to the discussion of this problem in an experimental way.

\section{Contrast of Syllables, Words and Connected Speech in Chinese and English}

Considering the articulatory and prosodic features of Chinese, Halliday (2007) did relevant analysis in terms of syllables. He pointed out that the syllable structures of Chinese are limited, and the possible combinations are only as follows: 1) CVVV or CVVC (a consonant, a semi-vowel, a vowel, and a close vowel or a nasal consonant, being put together in the order given); 2) CV, CVV, VC or CVC (two or three of the above elements being united in the same order).

Similarly, Duanmu (2007) proposed that in Standard Chinese, the two largest sizes of syllabic structures are CGVV (a consonant, a glide, a long vowel or a diphthong) and CGVC (a consonant, a glide, a vowel and a nasal consonant). The reason for these forms of combination is "the majority of Chinese words are monosyllabic" (Duanmu, 2007, p. 71), which ends with a vowel or a $/ \mathrm{n} /$ or $/ \mathrm{y} / \mathrm{sound}$.

In comparison, "English has a more complex syllable structure than most languages" (Roach, 2008, p. 79). On the one hand, it has not only monosyllabic words, but also polysyllabic words, which means many English words have more than one syllables. On the other hand, the combinations of sounds are much more complicated. The onset of an English syllable may consist of zero to three consonants, and the coda zero to four consonants. Therefore, the maximum phonological structure can be CCCVCCCC, provided that the consonant clusters and phonemic sequences conform to the English phonotactic constraints.

There is another phonological variation relevant to the two languages' different syllable structures. Chinese, as a kind of monosyllabic language, is syllable-timed. Each of its syllables (or words), except for a small number with light tone, is stressed with generally equal force and the same length of time (He, 2009; Zhang \& Yin, 2009) Comparatively speaking, English, with a majority of polysyllabic words, is a stress-timed language with stressed syllables occurring at roughly equal intervals (Giegerich, 1992). More time and force is spared on stressed syllables and less on unstressed ones when English is spoken. Chinese speakers, who are used to pronouncing each word clearly would be inclined to articulate in the same way when speaking in the target language, making their pronunciation sound non-native.

Additionally, the different rhythmic patterns of English and Chinese can be further verified by a suprasegmental feature called "juncture". Junctures are indicators marking boundaries between phonemes, syllables and words (He, 2009). In connected speech in different languages, the intelligible degree of junctures is different. In Chinese, junctures between words are inevitably noticeable because the rhythm is characterized by syllable-timing pattern and a majority of words share the same degree of emphasis. In English, by contrast, junctures between words are indistinct and unperceivable in many cases, especially before the words that are unstressed, and between the words whose onsets or codas can be joined by the preceding or following words. Making a connected speech in English is like singing in a legato way, with sounds gliding on smoothly with few pauses. Roach claims that "there is no silence to indicate word division and justify the space left in the transcription" (Roach, 2008, p. 144). A connected Chinese speech, in comparison, is articulated in a staccato way, with gaps clearly perceived between syllables. Duanmu supports this idea by stating that "syllable boundaries in Chinese are mostly unambiguous" (Duanmu, 2007, p. 71).

It is apparent that syllables, words and connected speech are closely correlated with respect to pronunciation, and the differences between Chinese and English in this aspect are various and remarkable. A number of previous studies merely centered their focus on analyzing the troubles foreign language learners generally have in pronouncing some single sounds, syllables or words (Chang, 2001; Flege, 1992; Huang, 2001), few have ever attended to the problems EFL learners may encounter in the pronunciation of connected speech, not to mention the relevant difficulties Chinese EFL learners may have due to the negative transfer of their mother tongue. Since these problems may not only affect a learner's pronunciation but also pose difficulties for his/her listening comprehension, it's necessary to do pertinent research and find ways to tackle them.

The following part will explicate some particular variations of English sounds in connected speech, which are generally weak among Chinese EFL speakers.

\section{Sound Variations in English Connected Speech}

The pronunciation of some English sounds is notably different between its occurrence in isolation and that in 
connected speech. The cause of variation is the common practice of liaison, weak form, elision, and assimilation in natural utterances, especially the ones spoken in fast rate and less formal style.

\subsection{Liaison}

In real English connected speech, syllable and word boundaries are frequently violated. So far as words belonging to one sense-group can have the onset of a word united with the coda of a preceding word, syllable restructuring is achieved, and words can be linked into one unit. There are various ways of liaison. The most ordinary forms are as follows:

\subsubsection{Linking and Intrusive / $\mathrm{r} /$}

If there is an "r" in the word-final position and it is followed by a word beginning with a vowel, the phoneme / $\mathrm{r} /$ would be vocalized to link the two words (Giegerich, 2005). For example: "clear it" is pronounced as /klørth/, and "fear it" as /frort/.

When the final sound of a word is $/ \mathbf{a} /, / \mathbf{o} /$ or $/ \mathbf{a} /$, and is followed by a word initiated by a vowel, an intrusive / $\mathbf{r} /$ will be inserted to blend the two words. For instance: "claw across" is read as /klp:rokros/, "far away" /f a:rowet, and "formula A"/f כ:mjuloret.

\subsubsection{Linking /j, w/}

In a fluently spoken speech, the sound $/ \mathbf{j}$ / is usually slightly inserted if a word ends with one of the following phonemes: /i:/, /I/, /aI/, /or/, or /ei/, and precedes a word with a vowel initial (Gruttenden, 2001), e.g. "we agree" /wi:jagri:/, "pretty and"/pritjaend/, "my ears"/maijlaz/, "boy and"/borjaend/, "say it"/serjit/.

Likewise, a slight /w/ sound may also be perceived between /u:/, /av/ or /ov/ and a following vowel, e.g. "too old"/tu:wauld/, "how about"/hauwabaut/, "go early"/gauws:lI/.

\subsubsection{Other Forms of Linking}

Another prevailing practice of link-up is to connect a vowel-initial word to its preceding consonant-ending word. Accordingly, "look after" is pronounced as /luka:fto/, "that is"/daets/, and "move it"/mu:vit/.

By associating adjacent sounds in the above ways, transition of junctures will sound smoother and more natural.

\subsection{Weak Forms of Function Words}

In connected speech, when function words are neither accented nor being in isolation or in the final place of a sentence, it is likely that their vowels will be obscured or reduced, and specific consonants be reduced (Wang, 2005). Examples are as below.

Table 1.

\begin{tabular}{|c|c|c|c|}
\hline Words & Accented & Unaccented & Sample sentence \\
\hline can & /kæn/ & $/ \mathbf{k} \boldsymbol{\prime} \mathbf{n} /, / \mathbf{k n} /$ & Can you help me? \\
\hline from & /from/ & /from/, /frm/ & She comes from New York. \\
\hline he & /hi:/ & $/ \mathbf{h} \mathbf{I} /, / \mathbf{I} /$ & Where is he going to? \\
\hline must & $/ \mathbf{m} \Lambda \mathbf{s t} /$ & /məst/, /məs/ & You must take it. \\
\hline some & $/ \mathbf{s} \mathbf{\Lambda} \mathbf{m} /$ & $/ \mathbf{s ə m} /, / \mathbf{s m} /$ & I need some fish. \\
\hline them & /ðеm/ & /ðәт/, /ðm/ & Tell them to come in. \\
\hline
\end{tabular}

As is illustrated in the above chart, the ways to weaken unaccented function words are to shorten long vowels, substitute /a/ sound for other vowels, and reduce specific vowels or consonants.

\subsection{Elision}

In fast casual speech, sounds may be deleted in word-final position. Among all the elisions, the final stops have the greatest tendency to be elided.

Firstly, a word-final explosive sound would become soundless if it's followed by an initial stop of the following word, e.g. "first time" is pronounced as /fasta m/, "keep peaceful" /ki:pi:sfl/.

Secondly, in case of "a final explosive + an initial affricate", the explosive is deleted, e.g. "meet George" /mi:d30:dZ, "odd judgment" /odzAdzmont/, "a magnetic chart"/omagnetitfa:t/.

Thirdly, if a stop is followed by a fricative sound, /h/, /f/, /v/, /s/, /z/, / / / or / / /, it is dropped, e.g. "clap hands" 
/klahaenz/, "stop fighting”/stpfattm/, "would say"/wused/, "ask them"/a:sðəm/.

Fourthly, an initial nasal sound would also make a preceding word-final stop soundless, e.g. "good night" /g unatt/, "help me"/helmi:/.

Fifthly, followed by sounds like /w/, /l/, and /r/, the final stop is deleted, e.g. "start working" /sta:ws:km/, "traffic lights"/traefilatts/, "keep reading”/ki:ri:dry/. (Gruttenden, 2001).

\subsection{Assimilation}

Assimilation is a phenomenon in regard to the different pronunciation of a phoneme when it neighbors a specific phoneme belonging to another word. Though forms of assimilation are varied, the present essay only introduces one kind which is most frequently explicated in Chinese phonetic and phonological textbooks.

As elision, assimilation may also occur across word boundaries in connected speech. Specifically, when a /t/ or $/ \mathrm{d} /$ sound glides to a $/ \mathrm{j} /$ sound in a smooth and quick way, the two sounds seem to happen simultaneously with segment boundary and they would be coalesced into a new sound $/ \mathrm{t} / \mathrm{or} / \mathrm{d} 3 /$ (Wang, 2005), e.g. "would you" /wod3/, "get your" /get J $3: /$. Similarly, when a /s/ or /z/ sound is followed by an initial /j/ sound, the two sounds combine, and a new sound $/ \mathrm{f} /$ or $/ 3 /$ will replace the original two phonemes, e.g makes you a hat /merkfu: a haet/, lose your key /luzo: ki:/.

\section{Experiment}

What have been elaborated on in Section 3 are different changing cues of some phonemes realized in connected speech. It is advised that Chinese learners who want to speak in an English native accent or understand rapid colloquial speeches from native speakers should learn these forms of variations.

In the following part, the writer is going to investigate what the real condition of intermediate Chinese EFL learners is in speech pronunciation, whether learners' mother tongue has any impact on their aspirating habits in making English connected speech, and whether listening competence would be influenced by the skills of pronunciation.

\subsection{Method}

\subsubsection{Subjects}

Fifty second-grade University students of English major took part in the study. They've learned English pronunciation in the first year and have been learning listening ever since. In other words, both skills have been learned and practiced.

\subsubsection{Materials}

Twenty-five sentences from a teaching material, "English Pronunciation \& Intonation for Communication" (Wang, 2005), were selected for the study. Since, in the material, they are particularly designed to help students practice pronouncing different kinds of variations, they innately meet the following criteria: 1) the words in the sentences are commonly used;2) the sentences are short with an average of about 8 words; 3 ) the sentences are read by native speakers at a rapid speed and in a colloquial manner; 4) each sentence contains at least one instance of variation. In summary, those sentences consist of 105 instances of variations, among which some items repeatedly occur in different sentences. The exact numbers of different variations are 10 assimilations, 16 elisions, 39 liaisons, and 40 weak forms.

In order to figure out how well students could decode and interpret the varied sounds in connected speech while listening, a blank-filling test of the 25 sentences was formulated, in which most words or phrases containing sound variations were removed.

\subsubsection{Procedures}

There were basically two stages in the experiment. At first, students were assigned to listen to the sentences twice and do corresponding blank-filling exercise. After handing in their test papers, they were required to read the sentences on the transcript and record their reading. At last, some participants were interviewed concerning their performances on both tests.

\subsubsection{Scoring Procedures}

In the listening exercise, the 105 sound variations were required to fill in. Successful recognition and correct spelling of the corresponding words led to accumulation of scores. Each item takes one point, so the full credit of the test paper was 105 points. Equally, the reading exercise was marked in the similar way. One point is gained if an allophonic item is correctly pronounced. The total score for reading is also 105 points. 
Fifty test papers and recording materials were respectively analyzed, which helped to check students' competence in understanding English connected speed and their performance in making fluent speeches. Then the written and reading tests were evaluated horizontally by comparing each student's written and reading performance, so as to examine whether one's pronunciation would have any impact on his corresponding comprehension of the spoken message.

\subsection{Results}

The data were collected from three facets, the scores of the two tests, the mistakes made in the listening test, and those in the reading test.

\subsubsection{Scores of the Two Tests}

Fifty subjects took part in both reading and listening tests. The mean, standard deviation and standard error difference of their scores are shown in Table 2.

Table 2. General results of the two tests

\begin{tabular}{lllll}
\hline Tests & $\mathrm{N}$ & Mean & Std. Deviation & Std. Error Difference \\
\hline Reading & 50 & 64.100 & 12.5978 & 1.7816 \\
Listening & 50 & 51.220 & 11.1306 & 1.5741 \\
\hline
\end{tabular}

In order to investigate if there's any connection between the subjects' reading and listening performance, a Pearson Correlation Test was taken.

Table 3. Results of Pearson correlation test

\begin{tabular}{llll}
\hline Pair & Number of Attendance & Correlation Coefficient & Significance \\
\hline Reading and Listening & 50 & $.435^{* *}$ & .002 \\
\hline **. Correlation is significant at the 0.01 level (2-tailed). & &
\end{tabular}

Furthermore, a regression analysis was done with the purpose to determine if the subjects' listening performance was dependent on their reading skills. The results are shown in Table 4.

Table 4. Results of regression analysis (Scores of the reading test are independent variables, and those of listening test are dependent variables.)

\begin{tabular}{llll}
\hline & Standardized Coefficients & $\mathrm{t}$ & Significance \\
\hline (Constant) & & 3.543 & .001 \\
Reading & .435 & 3.350 & .002 \\
\hline
\end{tabular}

4.2.2 Sample Mistakes Collected from the Reading Test

Table 5. Sounds unsophisticated articulated or mispronounced

\begin{tabular}{llllllll}
\hline Rank & Item/Items & Forms & $\mathrm{N} / \mathrm{P}$ & Rank & Item/Items & Forms & $\mathrm{N} / \mathrm{P}$ \\
\hline 1 & what I & $\mathrm{L}$ & $50 / 100 \%$ & 8 & but you & $\mathrm{WF} / \mathrm{A}$ & $45 / 90 \%$ \\
2 & should have/ left his & $\mathrm{L} / \mathrm{WF}$ & $50 / 100 \%$ & 9 & take it away & $\mathrm{L}$ & $44 / 88 \%$ \\
3 & (thinking of) you about & $\mathrm{L} / \mathrm{WF}$ & $48 / 96 \%$ & 10 & $\begin{array}{l}\text { thinking of/again and } \\
\text { again }\end{array}$ & $\mathrm{L} / \mathrm{WF}$ & $43 / 86 \%$ \\
4 & that & $\mathrm{WF}$ & $48 / 96 \%$ & 11 & office is & $\mathrm{L}$ & $42 / 84 \%$ \\
5 & $\begin{array}{l}\text { told him/ like us/ at eight// } \\
\text { turn right at }\end{array}$ & $\mathrm{L} / \mathrm{WF}$ & $47 / 94 \%$ & 12 & they ought to & $\mathrm{L} / \mathrm{WF}$ & $40 / 80 \%$ \\
6 & for a/ come and & $\mathrm{L} / \mathrm{WF}$ & $46 / 92 \%$ & 13 & made your/connect & $\mathrm{A}$ & $35 / 70 \%$ \\
7 & without a & $\mathrm{L}$ & $46 / 92 \%$ & 14 & $\begin{array}{l}\text { didn't you/heard your } \\
\text { n }\end{array}$ & $\mathrm{A}$ & $33 / 66 \%$ \\
\hline
\end{tabular}

Note . Forms $=$ forms of variation; $\mathrm{N} / \mathrm{P}=$ number and percentage of improper pronunciation among the subjects; $\mathrm{A}=$ assimilation; $\mathrm{E}=$ elision; $\mathrm{L}=$ liaison; $\mathrm{WF}=$ weak form. 
Varied sounds unsophisticatedly or falsely pronounced by more than $50 \%$ of the participants are described and listed in Table 5, ranking from maximum to minimum. In Table 6, the items collected in Table 5 are classified and enumerated.

As is illustrated in Table 5, five instances of assimilation, eighteen instances of liaison, and fourteen instances of weak form have been falsely or improperly pronounced by more than $50 \%$ of the participants. However, none elisions appear in this table.

In Table 6, the writer gives a summary of the results in Table 5, including the total number of each kind of variations in the test, the number of each kind of mistakes listed in Table 4, and the overall percentage of mistakes in relevant classifications.

Table 6. Number and percentage of mistakes of different classifications based on Table 5

\begin{tabular}{llll}
\hline Classification & N of M & Total Items & Percentage \\
\hline Assimilation & 5 & 10 & $50 \%$ \\
Liaison & 18 & 39 & $46 \%$ \\
Weak Form & 14 & 40 & $35 \%$ \\
Elision & 0 & 16 & $0 \%$ \\
\hline
\end{tabular}

Note. $\mathrm{N}$ of $\mathrm{M}=$ numbers of mistakes; Total Items = total items of the Sounds in this variation; Percentage $=$ amount of mistakes in the relevant classifications

\subsubsection{Sample Mistakes Collected from the Listening Test}

The typical mistakes made by more than $50 \%$ of the subjects are described and listed in Table 7, ranking from maximum to minimum.

Table 7. Mistakes in listening test

\begin{tabular}{llll}
\hline Rank & Items & Mistakes & $\mathrm{N} / \mathrm{P}$ \\
\hline 1 & play it & missing "it", or mistaking the phrase for "playing" or "played" & $50 / 100 \%$ \\
2 & that (a conjunction) & being unable to recognize "that" & $43 / 86 \%$ \\
3 & like us & missing "us" & $40 / 80 \%$ \\
4 & come for the party & missing "for", or replace it with "to" & $40 / 80 \%$ \\
5 & discuss it & missing "it", or mistaking the phrase for "discussed" & $39 / 78 \%$ \\
6 & they ought to & missing "they" or "ought" or both of them & $39 / 78 \%$ \\
7 & what I was & missing "I" and "was" & $38 / 76 \%$ \\
8 & but turn to the right & missing "but", or mistaking "but turn" for "pretend" or "attend" & $36 / 72 \%$ \\
9 & thinking of you about & missing "of"; missing "you" or "about" & $36 / 72 \%$ \\
10 & connect you & missing "you", or mistaking it for "ship, cheap, chip" & $36 / 72 \%$ \\
11 & should have & missing "have" & $35 / 70 \%$ \\
12 & but you & missing "you", or mistaking it for "she" & $31 / 62 \%$ \\
13 & office is & missing "is" or mistaking the phrase for "offices" & $28 / 56 \%$ \\
14 & ought to & missing "to" & $26 / 52 \%$ \\
15 & put you through & missing "you", or mistaking "put you" for "put she, putch, push" & $26 / 52 \%$ \\
16 & wait in & mistaking the phrase for "waiting" or "waited" & $25 / 50 \%$ \\
\hline
\end{tabular}

Note. $\mathrm{N} / \mathrm{P}=$ number and percentage of the mistakes among the subjects

\subsection{Analysis and Discussion}

Table 1 indicates that the majority of subjects did poorly in both tests. The mean scores of both reading and listening tests are low. The mean of the reading test is only a bit higher than the passing grade --- 63 points, and that of the listening test is lower than the passing grade. The scores of most subjects are between 70 s to 50 s for the reading test, and 60 s to 40 s for the listening test. 
Integrating the results of Table 2 and 3, it's found that the correlation coefficient of both tests is 0.435 , $\mathrm{p}=0.002<0.05$. Also, the reading test's standardized coefficient is 0.435 . Correspondingly, it can be inferred that there exists not only significant correlation between reading and listening performances, but also positive influence of reading results on listening results. Therefore, a tentative deduction can be made that poor reading performance may result in poor listening performance.

To further attest the correlation between one's reading habit and his listening apprehension, the concrete mistakes made in reading and listening tests are to be analyzed and compared.

\subsubsection{Analysis and Discussion on the Reading Test}

Taken together, the results in Tables 4 and 5 suggest that the subjects performed poorly in making connected speech. Mistakes are centered upon three facets: 1 ) combining a $/ \mathrm{t} /$ or $/ \mathrm{d} /$ sound with a $/ \mathrm{j} /$ sound, and assimilate them into $/ \mathrm{t} /$ or $/ \mathrm{d} 3 / ; 2$ ) pronouncing some function words in their proper weak forms; 3) linking syllables up whenever possible.

As is summed up in Table 5, 50\% of assimilations, $46 \%$ of liaisons and $35 \%$ of weak forms in the whole test were improperly read by more than $50 \%$ of subjects. Practice of elision was appreciably better. Few subjects made mistakes on any relevant items.

Concerning assimilations, negligence and mispronunciation were the major causes of mistakes. Though having learned assimilations, quite some subjects have forgotten that $/ \mathrm{t} /$ could be assimilated with $/ \mathrm{j} /$ into $/ \mathrm{t} / \mathrm{h}$, and $/ \mathrm{d} /$ with $/ \mathrm{j} /$ into $/ \mathrm{d} 3 /$. They kept reading the two words, like "didn't you", in a separate way. On the other hand, prevailing mispronunciations of assimilations were either having the $/ \mathrm{t} / \mathrm{t} / \mathrm{j} /$ combination articulated as $/ \mathrm{d} 3 /$, or the $/ \mathrm{d} /+/ \mathrm{j} /$ combination as $/ \mathrm{t} \mathrm{f} /$. Consequently, "made your" was mispronounced as $/$ mert $f(r) /$ and "connect you" as /kanekdzo/.

In connected speech, "what I", "without a", "office is", "discuss it", etc. are usually pronounced as /wotaI,

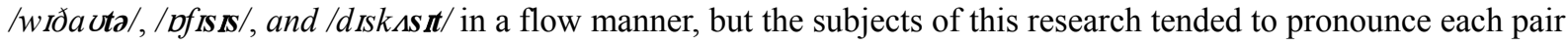
of words in a separate way with noticeable juncture. In reading the phrases "(thinking of) you about" and "they ought (to)", few subjects realized that they could link "you" and "about" with /w/, "they" and "ought" with /j/, for there're no such rules in Chinese. These phenomena embody the influence of mother tongue on the target language.

Phrases with both weak forms and liaisons like "should have", "left his", "told him", "like us", etc. are also frequently articulated in a detached way with equal force given to each word. Though the subjects have learned about weak forms in Grade 1, seldom had they ever put the knowledge into effect. Their ignorance of the weak forms of "have" $\rightarrow / \boldsymbol{o v} /$, "his" $\rightarrow /$ is/, "him" $\rightarrow / \mathrm{m} /$, and "us" $\rightarrow / \mathrm{os} /$ made them fail to join the words in a fluent and connected way.

Furthermore, in articulating phrases consisting of three words which can be joined up, like "take it away" and "again and again", the subjects were apt to unite the former two words, but left the latter two loosely discrete. In the post-test interview, the subjects admitted that they didn't realize that words could be linked up in a successive way.

An interesting but unexpected phenomenon is that very few subjects made mistakes in elision, compared with the high frequency of improper pronunciation of other variations. The reason for this situation manifested itself when the record of the reading test was carefully reexamined. It's discovered that elision not only occurred when a stop is in the word-final position followed by a word-initial consonant, but also happened when it's in the sentence-final position or followed by a vowel-initial word. Some mispronunciations of word-final stops are illustrated in Table 8.

Table 8. Instances of improper deletion of stops

\begin{tabular}{lll}
\hline Items & Mistakes & $\mathrm{N} / \mathrm{P}$ \\
\hline again and again & $/ \mathrm{d} /$ in "and" is deleted & $48 / 96 \%$ \\
watch it again & $/ \mathrm{t} /$ in "it" is deleted & $45 / 90 \%$ \\
what I & $/ \mathrm{t} /$ in "what" is deleted & $44 / 88 \%$ \\
without a word & $/ \mathrm{t} /$ in "without", and /d/ in "word" are deleted & $42 / 84 \% ; 10 / 20 \%$ \\
like us; take it away & $/ \mathrm{k} /$ in "like" and /t/ in "word" are deleted & $38 / 76 \%$ \\
\hline
\end{tabular}

Note. $\mathrm{N} / \mathrm{P}=$ number and percentage of mispronunciation among the subjects 
According to Chinese phonotactic constraints, only vowels and the two nasal consonants, $/ \mathrm{n} /$ and $/ \mathrm{n} /$, can occur in the syllable-final position (He, 2004, p. 76). Therefore, native Chinese speakers, profoundly governed by the articulating habit of their mother tongue, are habituated to deleting the English word-final plosives for almost all occasions unconsciously, which led to the high frequency of incorrect deletion of word-final stops, and the coincidentally correct elisions.

Nevertheless, as is shown in Table 8, the occurrence of mispronunciation is not equally manifested in all cases. For instance, 38 subjects dropped the phoneme /k/ in reading "like us", while none falsely deleted the same phoneme in reading "take it away". Similarly, in reading the phrase "without a word", 42 subjects dropped the stop /t/ in "without" but only 10 dropped /d/ in "word". In the post-test interview, relevant situation was investigated and some subjects explained that the stops embedded in word-final positions would not be ignored if they were prudent enough. This situation embodied that the subjects needed particular effort to enhance their awareness of the unfamiliar phonotactics of English.

\subsubsection{Analysis and Discussion on the Listening Test}

Though the linguistic knowledge would unavoidably have some impact on students' listening comprehension, the writer had minimized it to the greatest extent by careful selection of the material and meticulous arrangement of the experiment.

The findings in Table 7 indicate that the words frequently missed or misunderstood were the ones which are usually linked, weakened or assimilated in connected speech.

For instance, having been weaken and joined to the preceding words, "us" in "like us", "of" in "thinking of", "have" in "should have" failed to be distinguished and decoded by a majority of students, and were inevitably missed out. The same is true of other examples: "that", as a conjunction, is always weakened as /ðat/; "to" in the phrase "ought to" is usually weakened, linked up and elided as merely /o/ in /o:to/; "you" and "about" in "thinking of you about" are consistently linked up by an intrusive /w/ as /jowabaut/. When the phrases were read in a fast and gliding manner, the subjects who were unfamiliar with their variations could not recognize them.

Apart from omission, wrong deduction of the input owing to the interference of variations was also prevalent. Taking "discuss it", "office is" and "wait in" for examples, they were respectively mistaken as "discussed", "offices" and "waiting" or "waited". The vowel / $\mathbf{V}$ in the words "it", "is" and "in" were respectively retained, but the phrases were wrongly transformed to single words. The false comprehension was on account of the zero junctures between the words of each phrase. Having been accustomed to reading the phrases in a disconnected manner, the subjects inevitably felt alien when they were read in a different way.

Wrong inference of sound variations could also be found in assimilations. Examples are as follows: the phrases, "but you", "put you through" and "connect you" were wrongly interpreted as words with a $/ \mathbf{f} /$ or $/ \mathbf{t} /$ sound, and were mistaken as "but she", "put she through" or "putch/push through"; and "connect ship/cheap/chip";. Such misunderstanding was due to the unfamiliarity with the variations of assimilation.

Compared with the mistakes in both tests, it's found that the variations widely missed out or misunderstood in the listening test were also mispronounced by large percentage of participants in the reading test. The performances were so much in accord with one another that it could be attested that the subjects' reading habit did have a noticeable effect on their listening capability.

\section{Conclusion}

In conclusion, the results of this study suggest significant correlation of Chinese EFL learners' articulatory level with their performance of listening comprehension in regard to connected speech. Native Chinese learners, being so much accustomed to the distinctive Chinese phonetic and phonological features, are more or less influenced by their mother tongue while learning to speak a dramatically different language. They would find it even more difficult to imitate the pronunciation of fluent connected speech because rules of variations are involved. Successively, those who haven't had the rules learned by heart and practiced diligently would find it exceedingly hard to correctly apprehend the fast speeches spoken in the colloquial way. Since those rules are generally employed by native speakers in their daily communication, it is important for EFL learners to grasp them through voluntary and spontaneous practice.

As for English teachers, they should not only normalize students' pronunciation of individual sounds, but also instruct them to imitate fluent connected speech, to learn the practical skills of making and understanding natural communication. 


\section{References}

Chang, Y. (2001). A study of areas of English pronunciation which pose particular difficulties for Taiwanese EFL students based on the first students from two-year program of Trans world Institute of Technology. Journal Trans world Institute of Technology, 20, 95-108.

Cruttenden, A. (2001, 6th ed.). Gimson's Pronunciation of English. Edward Arnold (Publishers) Limited.

Duanmu, S. (2007, 2nd ed.). The Phonology of Standard Chinese. Oxford University Press Inc., New York.

Flege, J., Munro, M., \& Skelton, L. (1992). Production of the word-final English /t///d/ contrast by native speakers of English, Mandarin, and Spanish. Journal of the Acoustical Society of America, 92, 128-143. http://dx.doi.org/10.1121/1.404278

Giegerich, H. J. (2005, 8th printing). English Phonology. Cambridge University Press.

He, S. (2009, 7th printing). Contrastive studies of English and Chinese Languages. Shanghai Foreign Language Education Press.

Huang, T. L. (2001). Taiwanese and American English segmental phonemes: A contrastive study. Journal Jin-Wen Institute of Technology, 2, 29-55.

Roach, P. (2008). English Phonetics and Phonology: A Practical Course. Foreign Language Teaching and Research Press and Cambridge University Press.

Wang, G. (2005, 2nd ed.). English Pronunciation \& Intonation for Communication-A Course for Chinese EFL Learners. Higher Education Press.

Zhang, F., \& Yin, P. (2009). A study of pronunciation problems of English learners in China. Asian Social Science, 5, 141-146. http://dx.doi.org/10.5539/ass.v5n6p141

\section{Copyrights}

Copyright for this article is retained by the author(s), with first publication rights granted to the journal.

This is an open-access article distributed under the terms and conditions of the Creative Commons Attribution license (http://creativecommons.org/licenses/by/3.0/). 